\title{
Potential effect and mechanism of action of Zataria multiflora in liver disorders
}

\author{
Mohaddese Mahboubi ${ }^{1 \oplus}$ \\ ${ }^{1}$ Tabib Daru Company, Kashan, Iran \\ A - Research concept and design, B - Collection and/or assembly of data, C - Data analysis and interpretation, \\ $D$ - Writing the article, E - Critical revision of the article, F - Final approval of the article
}

Mohaddese Mahboubi. Potential effect and mechanism of action of Zataria multiflora in liver disorders. J Pre-Clin Clin Res. 2021; 15(4): 192-198. doi: 10.26444/jpccr/144424

\begin{abstract}
Introduction and Objective. Zataria multiflora Boiss or Iranian thyme (Lamiancea family) is traditionally used for the management of liver disorders. Due to the traditional importance of Z. multiflora in liver diseases, the aim of the review is to evaluate the preventive and therapeutic effects of $Z$. multiflora in liver diseases.

Review methods. Information was obtained from original peer reviewed articles published in scientific sources up to September 2021. Google Scholar, PubMed, Scopus, AMED, Cochrane Library electronic literature databases were investigated by the key words of 'Zataria multiflora', 'liver', 'hepato-protective', 'ROS', 'oxidative stress', and 'clinical trial'. The collected data aresummarized, categorized, analyzed, and discussed.

Brief description of the state of knowledge. The result of one clinical trial showed the efficacy and safety of Z. multiflora powder in non-alcoholic fatty liver diseases. Z. multiflora powder and its extracts reduced the liver oxidative stress induced by drugs, environmental toxins, cyst hydatid, and endogenous factors. The antioxidant activity of Z. multiflora essential oil is higher than its extracts or powder, due to the high content of thymol and carvacrol in its oil. Reactive oxygen species and oxidative stress play important roles in liver diseases; therefore, Z. multiflora and its extracts are regarded as natural antioxidants protecting the liver against free radicals.

Conclusion. Although there is one clinical study on Z. multiflora in non-alcoholic fatty liver diseases, large clinical trials are required to evaluate the efficacy and safety of $Z$. multiflora in liver diseases.
\end{abstract}

\section{Key words}

oxidative stress, NAFLD, liver, free radicals, plant, thyme

\begin{abstract}
Abbreviation
IBS - Irritable bowel syndrome; IBD - Inflammatory bowel disease; ROS - Reactive oxygen species; CAT - catalase; SOD super oxide dismutase; GPX - Glutathione peroxidase; GSH - Glutathione; RNS - nitrogen species; ALT - alanine transaminase; AST - aspartate transaminase; ALP - alkaline phosphatase; HepG2 - human liver cancer cell line; MDA - malondialdehyde; NAC - N-acetyl cysteine; LDH - lactate dehydrogenase; GST - Glutathione S-transferase; FRAP - ferric reducing ability of plasma; GGT - Gamma-glutamyl transferase; $\mathbf{O H}^{\mathbf{0}}$ - reactive hydroxyl radicals; hs-CRP - high-sensitivity C-reactive protein; FVC - Forced vital capacity; PEF - peak expiratory flow; HOMA.IR - Homeostatic Model Assessment of Insulin Resistance
\end{abstract}

\section{INTRODUCTION}

Z. multiflora Boiss ('Avishan Shirazi', 'Zaatar' or 'Iranian Thyme') is a flowering plant from the Lamiancea family with limited distribution in Iran, Pakistan, and Afghanistan [1]. In the traditional medicine of Iran, Z. multiflora is used as a diuretic, an anti-parasite, appetizer, anti-flatulence, anti-diarrhea, analgesic (teeth, joint, neuralgic, premature labour), and for the treatment of dysmenorrhea, sore throat, whooping cough, fever, catarrh, hysteria, infantile enuresis, dyspepsia, tonsillitis, and wounds [2, 3]. Rosmarinic acid, caffeic acid [4], multiflotriol, multiflorol, luteolin, p-hydroxy benzoic acid, dihydroxy aromadendrane, and essential oil have been isolated from the aerial parts of $Z$. multiflora. The yield of essential oil from $Z$. multiflora aerial parts is between $1-4 \%$. Phenolics (thymol and carvacrol) are the prominent compounds in Z. multiflora essential oil (Fig. 1)

Address for correspondence: Mohaddese Mahboubi, Tabib Daru Company, Second floor, Tabib Building, Bayan 6, Motahari St., 8715143330, Kashan, Iran E-mail: mahboubi1357@yahoo.com

Received: 12.08.2021; accepted: 02.12.2021; first published: 14.12.2021
[5]. The potency of $Z$. multiflora in gastrointestinal disorders (stomatitis, intra-oral, gastric and duodenal ulcers, Irritable Bowel Syndrome (IBS), Inflammatory Bowel Disease (IBD), colon cancer) [6, 7], Alzheimer [8], diabetes [9], pain [10], cough [11], infections $[12,13]$, and aphthous stomatitis have been reported (Fig. 2) [14].

Free radicals, reactive oxygen species (ROS) and oxidative stress play a crucial role in liver diseases [15]. Failure of the antioxidant defence system, and lipid peroxidation can change the membrane structures, and leads to tissue damage and the production of free radicals [16], Due to the antioxidant activity of $Z$. multiflora $[17,18]$, it can be a good candidate for the management of liver disorders. Therefore, the aim of this review was to evaluate the potential effects of Z. multiflora and its mechanism of action in the treatment of liver diseases.

Information for the review was obtained from original peer reviewed articles published in scientific resources up to Septembre 2021. Google Scholar, PubMed, Scopus, AMED, Cochrane Library electronic literature databases were investigated by the key words 'Zataria multiflora', 'liver', 'hepato-protective', 'ROS,' 'oxidative stress', and 'clinical 


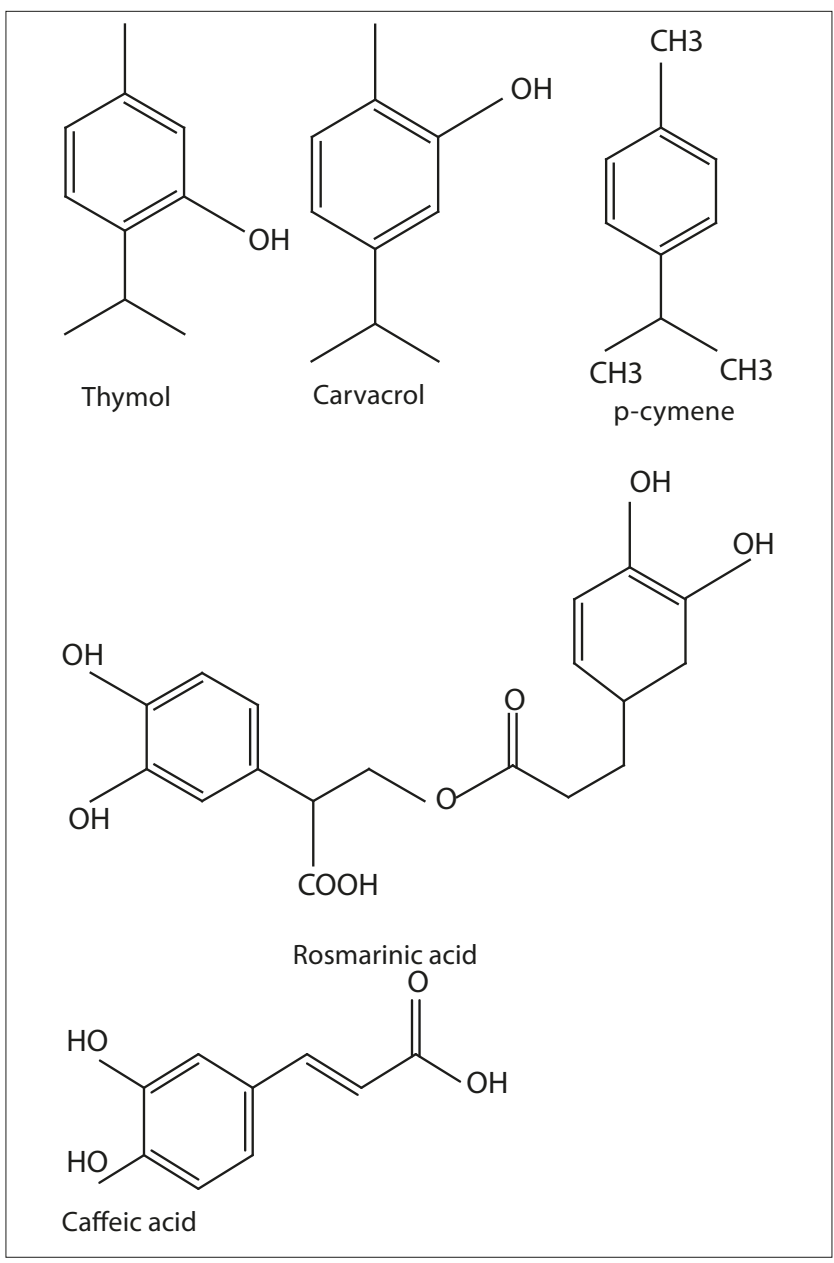

Figure 1. Structures of main components of Z. multiflora

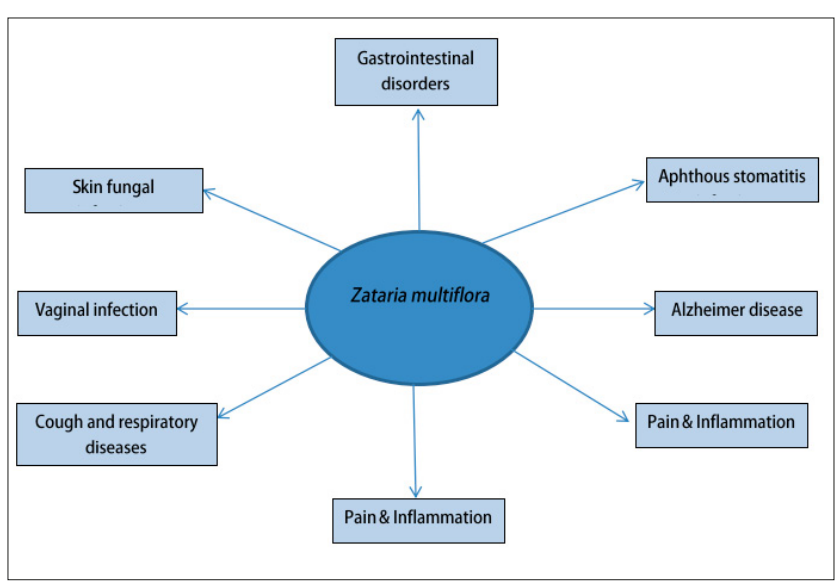

Figure 2. Z. multiflora and its efficacy in different ailments

trial'. The collected data are summarized, categorized, analyzed, and discussed.

The role of ROS in liver diseases. Exogenous (alcohol, drug, environmental toxins, virus, UV light) and endogenous (obesity, insulin resistance) factors are the major reasons for oxidative stress in liver. Oxidative stress in liver triggers the hepatic stellate, inflammasome, leads to damage the mitochondrial functions, DNA, proteins, and immune cell's infiltration, and the liver diseases (fibrosis/Cirrhosis, chronic hepatitis, hepatocellular carcinoma, and Steatosis)
[19]. Both non-enzymatic and enzymatic antioxidant systems are involved in reducing the oxidative stress. Antioxidant enzymes (catalase (CAT), super oxide dismutase (SOD), Glutathione peroxidase (GPx) and Glutathione (GSH)) are the biomarker of oxidative stress in the body and the use of various antioxidants and anti-oxidative therapies are used to treat the liver diseases.

\section{Z. multiflora and Oxidative Stress Caused by Drugs.}

The liver is the target of drug's toxicity, and the misuse of drugs is associated with production of free radicals (ROS), reactive nitrogen species (RNS) in the liver [20]. The misuse of paracetamol as an analgesic agent and adriamycin as an effective drug for cancers is associated with some toxicity and centrilobular hepatic necrosis $[21,22]$. The hepatotoxic effects of these drugs are mediated by activation of ROS and induction of oxidative stress in liver. Adriamycin disrupts the structural integrity of liver cells and increases the activity of liver enzymes (ALT, AST, ALP), and the serum malondialdehyde (MDA) level in the body, while the activity of antioxidant enzymes (SOD and CAT) reduce it [23]. Z. multiflora extract protects the liver against paracetamol [24], Adriamycin [25] induced hepatotoxicity in rats, by reducing the inflammatory cells, hepatic lesions, necrotic tissues, MDA in the body and modulation of ALT, AST, ALP, SOD, Cat and GPx $[24,25]$.

Z. multiflora had hepatoprotective effects against druginduced liver injuries in animal studies, Furthermore, Z. multiflora is a complementary alternative treatment, instead of acetaminophen or adriamycin as analgesic [26] and anti-cancer[27] agents to reduce the doses of drugs and their hepatotoxic effects.

Z. multiflora and oxidative stress caused by environmental toxins. Exposure of liver to different environmental chemicals and toxins has major effects on human health, and are the main reason for liver diseases, abnormalities, social and emotional injuries [28].

Malathion is an organophosphate insecticide, which significantly induces lesions and degeneration in the periportal area of liver tissues by increasing the plasma level of AST, ALT, and oxidative damages. Z. multiflora methanol extract had protective effect against malathion induced oxidative stress in mice by returning the activity of AST, ALT, GSH and antioxidant enzymes to the normal levels. $Z$. multiflora significantly inhibited the lipid peroxidation and improved the activity of SOD and CAT [29].

Halothane as a general anesthetic compound is used for anesthesia and its toxicity effect is associated with hepatitis or acute liver failures. The presence of antibodies against hepatocytes and liver oxidative stress through CYP450 with production of ROS [30], AST, ALT, ALP, LDH and total bilirubin are involved in its toxic effects. Pre-treatment of rats with $800 \mathrm{ppm}$ of $Z$. multiflora ethanol extract for 5 days significantly reduced the ALT, ALP, LDH levels in halothane induced hepatotoxic model, compared with control group [31].

Aflatoxins as secondary metabolites of some certain species of fungi are carcinogen and mutagen which and produce the oxidative stress, and acute liver toxicity [32]. Z. multiflora seeds $(20 \mathrm{~g} / \mathrm{kg})$ ameliorated the aflatoxin induced liver damage in broilers by improving the focal hepatic necrosis, parenchymal and mononuclear cell aggregation [33]. 
The toxic effects of metallic nanoparticles on liver cells are associated with production of ROS and other free radicals in the body, leading to a reduction in the cell survival rate and the induction of hepatocellular necrosis [34]. Treatment of animals with iron nanoparticles significantly inactivated the CYP450, which is associated with increase in activity of AST, and reduction in activity of Glutathione S-transferase (GST). Thyme essential oil returned the activity of GST, AST to normal levels $(p<0.05)$, with no effect on CYP 450 protein and other liver enzymes. The protective effect of thyme oil was confirmed by intact vacuole, small necrosis and low hepatocellular damage in histopathological samples of animals, compared to control group[35].

GST is responsible for the production of different enzymes, which catalyzes the carcinogen and cytotoxic compounds. Normal activation of GST and modulation of CYP450 by the protective effect of thyme oil against iron nanoparticles is associated with the normal activity of different enzymes involved in catalyzing the carcinogen and cytotoxic compounds.

The hepatoprotective effects of $Z$. multiflora ethanol extract was confirmed against cyclophosphamide induced hepatotoxicity in mice, which was exhibited by improvement in liver enzymes and liver histopathological features[36].

According to the results of pharmacological studies, Z. multiflora protects the liver against oxidative stress caused by contact with environmental toxins, such as halothane, metal nanoparticles, aflatoxins, and malathion; this protective effect is mediated by modulation of the liver and antioxidant enzymes, and reduction of produced free radicals.

\section{Z. multiflora and endogenous (obesity, insulin resistance)}

factors. Non-alcoholic fatty liver disease (NAFLD) as a chronic liver disorder is associated with hypertension, obesity, dyslipidemia and type 2 diabetes mellitus [37]. The antidiabetic effects of $Z$. multiflora essential oil were confirmed against Streptozotocin-induced diabetic rats. Z. multiflora essential oil (orally) significantly increased the total protein and insulin, and reduced high plasma glucose, ALP, AST, and ALT in Streptozotocin-induced diabetic rats. The free radical scavenging effects of $Z$. multiflora essential oil protects the rats against diabetic damage [38]. In addition to the antidiabetic effect of $Z$. multiflora essential oil, its ethanol extract significantly reduced the blood glucose level in diabetic mice and significantly improved the insulin, ALT, and AST levels in treated animals. The improvement in liver enzymes and blood glucose was associated with significant reduction in hyperglycaemia, inflammation, and oxidative stress. $Z$. multiflora ethanol extract increased the activity of SOD, CAT and reduced the MDA and TNF- $\alpha$ in diabetic mice. In the presence of $Z$. multiflora ethanol extract, a significant improvement in cholesterol, total glyceride, HDL, and LDL levels was observed, while no signs of pathological damage were found in the liver of treated mice [39]. Significant reduction of LDL-cholesterol and activation of triglyceride lipase enzyme reduced the lipid accumulation in the liver of healthy animals, without any effects on serum level of AST, ALT and ALP [40].

Insulin resistance as key feature of type 2 diabetes in the body is associated with hyperglycaemia, hyper-insulinaema, and dyslipidaemia. Z. multiflora aqueous extract $(1,000 \mathrm{mg} / \mathrm{kg})$, similar to pioglitazone $(10 \mathrm{mg} / \mathrm{kg})$, increased the insulin, glucose, triglyceride and PPAR $\gamma$ levels in the liver, and reduced adiponectin and Homeostatic Model Assessment of Insulin Resistance (HOMA.IR) levels in fructose-fed insulin resistant rats, but with a difference in the mechanism of actions: pioglitazone significantly reduced the total free fatty acids level $(\mathrm{p}<0.05)$, while $Z$. multiflora had no effect on total free fatty acid content [41]. The anti-hyperglycaemic activity of $Z$. multiflora is superior to its effect on insulin secretion. Inhibition of liver gluconeogenesis and increase of free fatty acids muscle oxidation by increase of adiponectin and PPAR $\gamma$ protein and translocation of GLUT4 in adipose tissue improved the insulin resistant and insulin sensitivity in insulin resistant animals. Therefore, $Z$. multiflora may have 3 mechanism of anti-hyperglycemic effect, which is mediated by a direct insulin-like effect, increase in the expression of $\operatorname{PPAR} \gamma$ and adiponectin.

Z. multiflora and hepatic hydatid cysts. Hydatid cyst, especially hepatic hydatid infection, is caused by Echinococcus sp., especially E. granulosus, which is the most common infection [42].

Administration of $Z$. multiflora water $(40 \mathrm{ml} /$ liter in drinking water for 8 months) reduced the cyst sizes and weights in infected mice with hydatid cyst, and damaged the morphology and germinal layers of cysts similar to albendazole $(150 \mathrm{mg} / \mathrm{Kg})[43,44]$. The growth and reproduction of protoscolices are mediated by germinal layers, as an important organ for infectivity of hydatid cysts. Z. multiflora can destroy the germinal layers of protoscolices and separate the germinal from laminated layers and produce the vacuolated laminated layers [45]. Furthermore, $Z$. multiflora with the immune-modulatory effects and increase of NO production can protect the Kupffer, fatstoring, and endothelial liver cells, which lead to activation of macrophages, T-cells and production of cytokines in infected animals with hydatid cyst [46].

Z. multiflora aqueous extract had protective effects against long-term administration of albendazole-induced hepatic injury in mice Balb/C [47]. Although co-administration of $Z$. multuiflora with albendazole significantly reduced the deleterious effects of albendazole on liver, further pharmacological and clinical studies are required on different extracts of $Z$. multiflora against albendazole-induced hepatic injuries in order to reduce the effective dose or length of treatment with albendazole.

Hepato-protective effects of $Z$. multiflora in clinical studies. Although, Z. multiflora is known as a suitable alternative hepatoprotective agent in animal studies, and its efficacy should be confirmed in human studies. There is one 12-week randomized double blind placebo controlled clinical trial on the efficacy and safety of $700 \mathrm{mg} Z$. multiflora powder $(\mathrm{n}=45)$, administered twice daily in comparison with placebo $(\mathrm{n}=40)$ in patients $(\mathrm{n}=85)$ with NAFLD. Z. multiflora powder significantly reduced the serum insulin level $(\mathrm{p}=0.03)$ and insulin resistance $(p=0.023)$ of patients, with no effect on ALT, high-sensitivity C-reactive protein (hs-CRP), TNF- $\alpha$, lipid profiles and the grade of liver fat, compared with placebo. The treatment was safe and well tolerated [48].

Insulin resistance is known as one important risk factor for pathogenesis of NAFLD. Although, the daily dose of $1,400 \mathrm{mg} \mathrm{Z}$. multiflora powder for 12 weeks reduced the insulin resistance, serum insulin with no effects on other 
factors, the short length of treatment, and no assessment of daily calorie intake, was the limitation of this clinical study. Thus, the use of $Z$. multiflora essential oil, or its ethanol extract and daily calorie assessment of patients, are recommended for future clinical studies.

\section{The antioxidant effects of $Z$. multiflora in clinical studies.} Sulfur mustard is the reason for injuries in different organs of the body, especially in the liver. Forty-seven veterans who were exposed to sulfur mustard, were enrolled in a clinical trial, and randomly divided into 3 groups administered $5 \mathrm{mg} / \mathrm{kg} \mathrm{Z}$. multiflora $(\mathrm{n}=17), 10 \mathrm{mg} / \mathrm{kg} \mathrm{Z}$. multiflora $(n=14)$, and a placebo $(n=16)$. The volunteers were given the treatments 3 times a day for 2 months, together with their previous treatments (inhaled salbutamol, corticosteroid, and theophylline). However, during 2 months of treatments, Z. multiflora had no effect on other haematological parameters, placebo had no effects on the level of thiol, MDA, SOD and CAT activity, while Z. multiflora significantly increased the level of thiol, CAT, SOD and decreased the MDA level, compared to the baseline. The treatment of patients with $Z$. multiflora ethanol extract significantly decreased the serum level of TNF- $\alpha$, MCP-1, EGF, and VEGF [49]. The potency of $Z$. multiflora in increase in the activity of antioxidant enzymes and reduction in MDA level was confirmed in the current clinical study.

Mechanism of action for hepatoprotective effects of Zataria multiflora. The results of pharmacological studies on the hepatoprotective effects of $Z$. multiflora are related to its ability to scavenge the free radicals, and its antioxidant activities and their effects on inflammatory cytokines in the body. Z. multiflora methanol extract significantly reduced the IL- 6 expression, which is involved in some inflammatory diseases, such as obesity, diabetes and arthritis rheumatoid [50].

The antioxidant activity of $Z$. multiflora extracts is related to its carvacrol and thymol content: carvacrol had protective effects against d-galactosamine- [51] and thioacetamideinduced hepatotoxicity in rats $[52,53]$. The inflammation and oxidative stress of acetaminophen- exposed HepG2 cells were inhibited by thymol and carvacrol in a dosedependent manner. Thymol and carvacrol increased the activity of anti-oxidant enzymes and GSH level, and reduced the levels of ALT and LDH and pro-inflammatory cytokines (TNF- $\alpha$, IL-1 $\beta$ ) in acetaminophen- induced HepG2 cell lines [54]. Administration of $20 \mathrm{mg} / \mathrm{kg}$ carvacrol for 28 days significantly reduced the MDA level, serum level of ALP, ALT, and AST in adriamycin-exposed Wistar rats [25]. Carvacrol reduced the lipid peroxidation and MDA by activation of anti-oxidant enzymes (SOD, CAT and GPx) in cerulean-induced acute pancreatitis in animals. The levels of 8-OH-dG as a marker of DNA oxidative stress, was lower in carvacrol treated acute pancreatitis than in the acute pancreatitis animal model. An increase in glycogen content of hepatocytes and reduction in fibrosis was observed in carvacrol treated acute pancreatitis animals [55]. The protective effect of carvacrol against MDA production was mediated via post transcriptional action by suppressing the HMG-CoA reductase in the liver [56].

Carvacrol had chemo-preventive effects against diethylnitrosamine (DEN-induced liver cancer in rats). The preventative effects of carvacrol against lipid peroxidation and its protective effects against the antioxidant system inhibited hepatic cell damage in DEN-induced hepatocellular carcinogenesis [57]. Carvacrol scavenges the free radicals by activation of host antioxidant defence mechanisms and drug metabolizing enzyme, detoxifies the free radicals and reduces the lipid peroxidation [58].

The effects $1.2 \mathrm{mg} / \mathrm{kg}$ per day of carvacrol on 10 patients exposed to sulfur mustard in comparison with placebo for two months significantly increased the activity of antioxidant enzymes (SOD, CAT), and thiol level and reduced the MDA level in patients [59]. Reduction in inflammatory cytokines (IL-2, IL-4, IL-6, IL-8) and a significant increase in IL-10, IFN- $y$, IFN- $y /$ IL-4 ratio, were observed after treatment with carvacrol after two months [60].

Thymol exhibited hepatoprotective effects against carbon tetrachloride (CCL)- induced hepatotoxicity in mice [61] and $\mathrm{H}_{2} \mathrm{O}_{2}$ induced cytotoxicity in HepG2 cell lines [62]. Thyme aqueous extract completely protected the G6PD against nitroso-arginine and nitroso-cysteine. Thyme extract protected the activity of the G6PD enzyme and inhibited the production of cellular reactive oxygen species to inhibit the RBC hemolysis [63]. Strong radical scavenging activity was reported for thymol with $\mathrm{IC}_{50} 0.169 \mathrm{mg} / \mathrm{ml}$ [64]. The hepatoprotective potency of treatment for thymol was better than carvacrol in acetaminophen exposed HepG2 [54]. Therefore, the hepatoprotective effects of $Z$. multiflora, thymol and carvacrol are related to the reduction of oxidative stress, improvement of antioxidant defence, and inhibition of pro-inflammatory cytokines.

\section{CONCLUSIONS}

There is one clinical trial on efficacy and safety of Z. multiflora in NAFLD. The investigation on mechanism of action of $Z$. multiflora in liver disorders exhibited that liver as the vital organ in the body is the target of oxidative stress and free radicals and there is a positive correlation between the liver injury and oxidative stress. Z. multiflora preparations scavenged the free radicals and acted as antioxidant agent (Table 1). Z. multiflora extracts protected the liver against drug (acetaminophen, adriamycin), environmental toxins (malathion, halothane, aflatoxins, etc.), endogenous factors (metabolic disorders, aging), and hydatid cyst (Figure 3). Z. multiflora powder significantly reduced the blood GSH, MDA, liver SOD [65], TBARS concentration [66] and glycogen content and improved the liver function by increasing the serum ALT, AST, and ALP enzymes and total antioxidant status in liver [67].

$Z$. multiflora methanol, ethanol or aqueous extracts have been used as hepatoprotective agent in most preclinical studies, and its liver protective effects are related to the thymol and carvacrol content. Among different extracts of Z. multiflora, its essential oil is rich of thymol and carvacrol, and has higher antioxidant activities; therefore, Z. multiflora essential oil can be used in pharmacological and clinical studies for its liver protective effects.

\section{Acknowledgments}

The review is an in-house, non-financially supported study by one author. No consent was necessary for publication. 
Table 1. Hepato-protective effects of $Z$. multiflora against endogenous factors, and oxidative stress in animal models

\begin{tabular}{|c|c|c|c|c|}
\hline Compound & Dose & Animal model & Results & References \\
\hline $\begin{array}{l}\text { Z. multiflora } \\
\text { methanol } \\
\text { extract }\end{array}$ & $100,200,400 \mathrm{mg} / \mathrm{kg}$ & $\begin{array}{l}\text { Paracetamol }(2 \mathrm{~g} / \mathrm{kg}) \text { induced hepatotoxicity } \\
\text { in male Wistar rats }\end{array}$ & $\begin{array}{c}\downarrow \\
\downarrow \text { Inflammatory cells } \\
\downarrow \text { Hepatic lesions } \\
\downarrow \text { Necrotic tissues } \\
\downarrow \text { MDA level } \\
\uparrow \text { SOD, Cat and GPx to normal level } \\
\downarrow \text { ALT, AST, ALP to the normal values }\end{array}$ & [24] \\
\hline $\begin{array}{l}\text { Z. multiflora } \\
\text { ethanol extract }\end{array}$ & $200 \mathrm{mg} / \mathrm{kg}$ & Adriamycin $(5 \mathrm{mg} / \mathrm{kg})$ in male Wistar rats & $\downarrow$ Liver ALT, ALP and MDA levels & {$[25]$} \\
\hline $\begin{array}{l}\text { Z. multiflora } \\
\text { methanol }\end{array}$ & $200 \mathrm{mg} / \mathrm{kg}$ & Malathione induced oxidative stress in mice & $\begin{array}{c}\downarrow \text { AST and ALT to normal level } \\
\downarrow \text { lipid peroxidation } \\
\uparrow \text { SOD , CAT }\end{array}$ & [29] \\
\hline $\begin{array}{l}\text { Z. multiflora } \\
\text { ethanol extract }\end{array}$ & 800 ppm for 5 days & $\begin{array}{l}\text { Halothane induced hepatotoxicity Wistar } \\
\text { albino rat's model. }\end{array}$ & $\downarrow$ ALT, ALP, LDH levels & [31] \\
\hline $\begin{array}{l}\text { Z. multiflora } \\
\text { seeds }\end{array}$ & $20 \mathrm{~g} / \mathrm{kg}$ & Anti-aflatoxin $B_{1}$ effects in broilers & $\begin{array}{c}\downarrow \text { Liver damage } \\
\downarrow \text { Focal area of hepatic necrosis } \\
\downarrow \downarrow \text { Parenchymal } \\
\downarrow \text { Mononuclear cell aggregation }\end{array}$ & [33] \\
\hline $\begin{array}{l}\text { Thymus vulgaris } \\
\text { essential oil }\end{array}$ & $100,200 \mathrm{mg} / \mathrm{kg}$ b.w & Iron nanoparticles & $\begin{array}{c}\uparrow \text { CYP } 450 \text { protein level activity } \\
\downarrow \text { GST, AST to normal levels } \\
\text { No vacuole destruction }\end{array}$ & [35] \\
\hline $\begin{array}{l}\text { Z. multiflora } \\
\text { ethanol extract }\end{array}$ & $\begin{array}{c}50,100,200, \\
\text { or } 400 \mathrm{mg} / \mathrm{kg} \\
\text { for } 7 \text { consecutive }\end{array}$ & $\begin{array}{l}\text { cyclophosphamide induce hepatotoxicity } \\
\text { in mice }\end{array}$ & $\begin{array}{c}\downarrow \downarrow \text { ALP, AST and ALT } \\
\text { improvement of liver histopathological features }\end{array}$ & [36] \\
\hline $\begin{array}{l}\text { Z. multiflora } \\
\text { essential oil }\end{array}$ & $50,100 \mu \mathrm{l} / \mathrm{kg}$ for 28 days & Streptozotocin induced diabetes in rats & $\begin{array}{c}\uparrow \text { Total protein, insulin, } \\
\downarrow \text { plasma glucose, ALP, AST, ALT } \\
\text { Scavenge the oxygen and nitrogen radicals }\end{array}$ & [38] \\
\hline $\begin{array}{l}\text { Z. multiflora } \\
\text { ethanol extract }\end{array}$ & $\begin{array}{c}250,500 \\
1000 \mathrm{mg} / \mathrm{kg} / \text { day } \\
\text { for } 28 \text { days }\end{array}$ & Streptozotocin induced diabetes in rats & $\begin{array}{c}\downarrow \text { Blood glucose level } \\
\uparrow \text { Insulin level } \\
\downarrow \text { Serum level of ALT, AST } \\
\downarrow \text { Hyperglycaemia } \\
\downarrow \text { Inflammation } \\
\downarrow \text { Oxidative stress. } \\
\uparrow \text { SOD, CAT } \\
\downarrow \text { MDA, TNF-a }\end{array}$ & [39] \\
\hline $\begin{array}{l}\text { Z. multiflora } \\
\text { ethanol extract }\end{array}$ & $\begin{array}{c}100,200,300 \\
400 \mathrm{mg} / \mathrm{kg} \text { for } 28 \text { days }\end{array}$ & Rats & 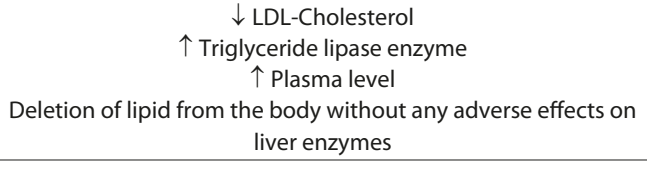 & [40] \\
\hline $\begin{array}{l}\text { Z. multiflora } \\
\text { aqueous extract }\end{array}$ & $1000 \mathrm{mg} / \mathrm{kg}$ & Fructose fed insulin resistant rats & $\begin{array}{c}\uparrow \text { Insulin, glucose, triglyceride and PPARy levels } \\
\downarrow \text { Level of adiponectin and HOMA.IR } \\
\text { No effect on total free fatty acids content } \\
\text { Effect of Z. multiflora on PPARy was on protein level, not on } \\
\text { mRNA level, but had no effect on GLUT.4 protein. }\end{array}$ & [41] \\
\hline
\end{tabular}

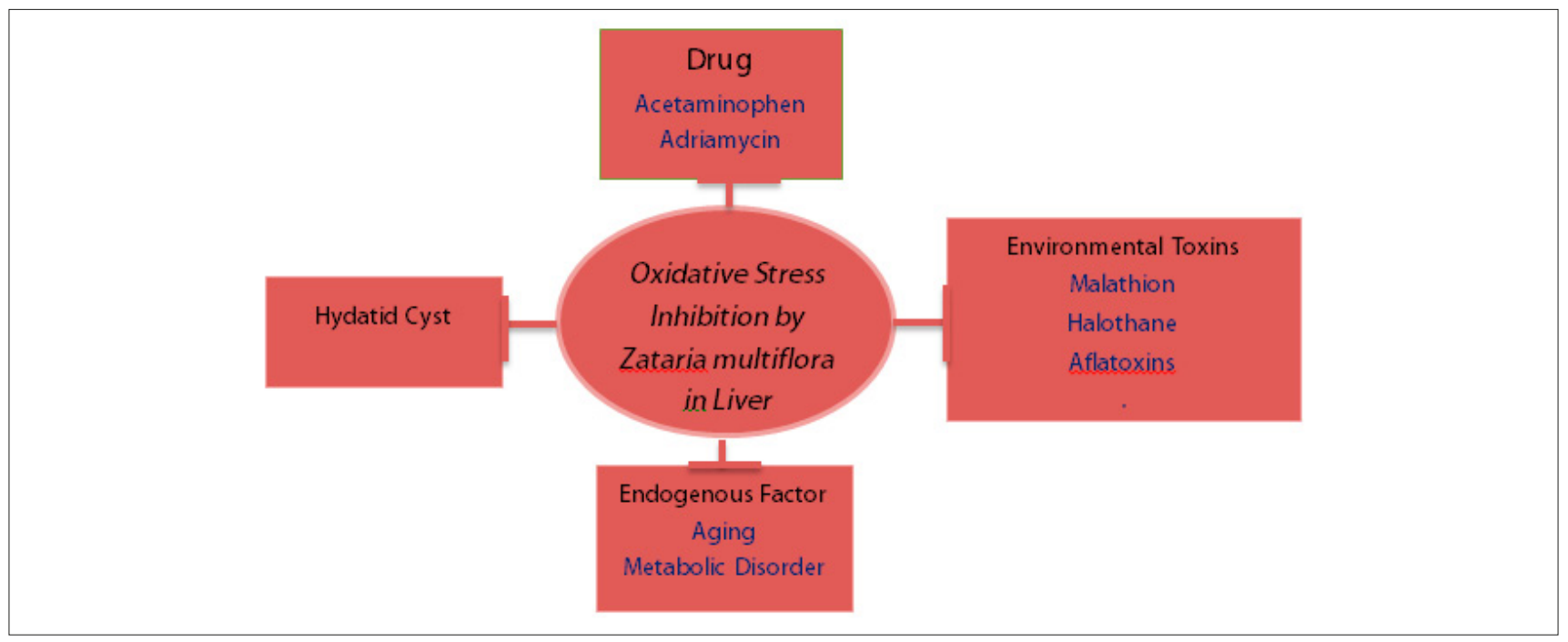

Figure 3. Hepato-protective effects of Z. multiflora by inhibition of oxidative stress 


\section{REFERENCES}

1. Mozaffarian V. Dictionary of Iranian plant names. Tehran, Iran: Farhang-E-Moaser; 1996.

2.Ali MS, Saleem M, Ali Z, et al. Chemistry of Zataria multiflora (Lamiaceae). Phytochemistry. 2000; 55: 933-936. doi: 10.1016/s00319422(00)00249-1

3.Zargari A. Medicinal plants. Tehran, Iran: Tehran University Publication; 1990.

4. Bernard F, Hassonpoor H, Shaker-Bazanov H. The effect of carbohydrate type and illumination mode on proline, caffeic acid and rosmarinic acid accumulation in two lines of Zataria multiflora callus tissues. Acta Horticulturae. 2006; 723:289-292. doi: 10.17660/ActaHortic.2006.723.39

5. Aghamohammadi A, Azadbakht M, Hosseinimehr SJ. Quantification of thymol content in different extracts of Zataria multiflora by HPLC method. Journal Pharmaceutical and Biomedical Research. 2016; 2 8-13. doi: 10.18869/acadpub.pbr.2.1.8

6. Shomali T. Chapter 17 - Zataria multiflora and Gastrointestinal Tract Disorders. In: Watson RR, Preedy VR, Hrsg. Dietary Interventions in Gastrointestinal Diseases. Academic Press; 2019: 209-212. doi: https:// doi.org/10.1016/B978-0-12-814468-8.00017-X

7. Mahboubi M. Therapeutic Potential of Zataria multiflora Boiss in Treatment of Irritable Bowel Syndrome (IBS). Journal of Dietary Supplements 2019; 16: 119-128. doi: 10.1080/19390211.2017.1409852

8. Majlessi N, Choopani S, Kamalinejad M, et al. Amelioration of amyloid $\beta$-induced cognitive deficits by Zataria multiflora Boiss. essential oil in a rat model of Alzheimer's disease. CNS Neurosci Ther. 2012; 18 : 295-301. doi: 10.1111/j.1755-5949.2011.00237.x

9. Kavoosi G, Balotf S. Zataria multiflora essential oil reduces diabetic damages in streptozotocin-induced diabetic rats. Clinical Biochemistry. 2011; 10: 17632-17639.

10. Hosseinzadeh H, Ramezani M, Salmani G. Antinociceptive, antiinflammatory and acute toxicity effects of Zataria multiflora Boiss extracts in mice and rats. J Ethnopharmacol. 2000; 73: 379-385. doi: $10.1016 / \mathrm{s} 0378-8741(00) 00238-5$

11. Mahboubi M. Management of acute cough by Zataria multiflora Boiss as an alternative treatment. J Integr Med. 2018; 16: 20-25. doi: 10.1016/j. joim.2017.12.006

12. Mahboubi M. Systematic review: The potency of Zataria multiflora Boiss in treatment of vaginal infections. 2018; 22: 76-83.

13. Khosravi RA, Shokri H, Farahnejat Z, et al. Antimycotic efficacy of Iranian medicinal plants towards dermatophytes obtained from patients with dermatophytosis. Chinese Journal of Natural Medicines. 2013; 11 : 43-48. doi: https://doi.org/10.1016/S1875-5364(13)60006-0

14. Mansoori P, Hadji Akhoondi A, Ghavami R, et al. Clinical evaluation of Zataria multiflora essential oil mouthwash in the management of recurrent Aphthous Stomatitis. Daru Journal of Pharmaceutical Sciences. 2002; 10: 74-77.

15. Diesen DL, Kuo PC. Nitric oxide and redox regulation in the liver: Part I. General considerations and redox biology in hepatitis. J Surg Res. 2010; 162: 95-109. doi: 10.1016/j.jss.2009.09.019

16. Lobo V, Patil A, Phatak A, et al. Free radicals, antioxidants and functional foods: Impact on human health. Pharmacognosy Reviews. 2010; 4: 118-126. doi: 10.4103/0973-7847.70902

17. Saei-Dehkordi SS, Tajik H, Moradi M, et al. Chemical composition of essential oils in Zataria multiflora Boiss. from different parts of Iran and their radical scavenging and antimicrobial activity. Food and Chemica Toxicology. 2010; 48: 1562-1567. doi: 10.1016/j.fct.2010.03.025

18. Sharififar F, Derakhshanfar A, Dehghan-Nudeh G, et al. In vivo antioxidant activity of Zataria multiflora Boiss essential oil. Pakistan Journal of Pharmaceutical Sciences. 2011; 24: 221-225.

19. Li S, Tan H-Y, Wang N, et al. The role of oxidative stress and antioxidants in liver diseases. International Journal of Molecular Sciences. 2015; 16 : 26087-26124. doi: 10.3390/ijms161125942

20. Videla LA. Oxidative stress signaling underlying liver disease and hepatoprotective mechanisms. World J Hepatol. 2009; 1: 72-78 doi: 10.4254/wjh.v1.i1.72

21. Mahadevan SB, McKiernan PJ, Davies P, et al. Paracetamol induced hepatotoxicity. Arch Dis Child. 2006; 91: 598-603. doi: 10.1136/ adc. 2005.076836

22. Sterrenberg L, Julicher RHM, Bast A, et al. Adriamycin stimulates NADPH-dependent lipid peroxidation in liver microsomes not only by enhancing the production of $\mathrm{O}_{2}$ and $\mathrm{H}_{2} \mathrm{O}_{2}$, but also by potentiating the catalytic activity of ferrous ions. Toxicology Letters. 1984; 22: 153-159. doi: https://doi.org/10.1016/0378-4274(84)90059-6

23. Ahmed MB, Khater MR. Evaluation of the protective potential of Ambrosia maritima extract on acetaminophen-induced liver damage.
Journal of Ethnopharmacology. 2001; 75: 169-174. doi: https://doi org/10.1016/S0378-8741(00)00400-1

24. Ahmadipour A, Sharififar F, Najafi A, et al. Preventive effect of methanolic extract of Zataria Multiflora Boiss on liver toxicity of paracetamol in rats. J Med Life. 2015; 8: 270-274.

25. Mohebbati R, Paseban M, Soukhtanloo M, et al. Effects of standardized Zataria multiflora extract and its major ingredient, carvacrol, on adriamycin-induced hepatotoxicity in rat. Biomedical Journal. 2018 41: 340-347. doi: https://doi.org/10.1016/j.bj.2018.10.008

26. Hosseinzadeh H, Ramezani M, Salmani G. Antinociceptive, antiinflammatory and acute toxicity effects of Zataria multiflora Boiss extracts in mice and rats. Journal of ethnopharmacology. 2000; 73 379-385. doi: 10.1016/s0378-8741(00)00238-5

27. Ahani N, Sangtarash MH, Alipour Eskandani M, et al. Zataria multiflora Boiss essential oil induce apoptosis in two human colon cancer cell lines (HCT116 \& SW48). Iranian journal of public health. 2020; 49: 753-762.

28. Piazza MJ, Urbanetz AA. Environmental toxins and the impact of other endocrine disrupting chemicals in women's reproductive health. JBRA Assisted Reproduction. 2019; 23: 154-164. doi: 10.5935/1518 0557.20190016

29. Ahmadipour A, Sharififar F, Pournamdari M, et al. Hepatoprotective effect of Zataria Multiflora Boiss against malathion-induced oxidative stress in male rats. Oriental Pharmacy and Experimental Medicine. 2016; 16: 287-293. doi: 10.1007/s13596-016-0238-6

30. Habibollahi P, Mahboobi N, Esmaeili S, et al. Halothane-induced hepatitis: A forgotten issue in developing countries: Halothane-induced hepatitis. Hepatitis monthly. 2011; 11: 3-6.

31. Sakhaee E, Emadi L, Azari O, et al. Evaluation of the beneficial effects of Zataria Multiflora Boiss in halothane-induced hepatotoxicity in rats. Advances in Clinical and Experimental Medicine. 2011;20: 23-29.

32. Benkerroum N. Chronic and acute toxicities of aflatoxins: Mechanisms of action. Int J Environ Res Public Health. 2020; 17: 423. doi: 10.3390/ ijerph17020423

33. Makki OF, Omidi A, Nik HA, et al. Anti-aflatoxin B1 effects of Shirazi thyme (Zataria multiflora) in broilers: evaluation of performance and liver histopathology. 2016; 6: 6090.

34. Yao Y, Zang Y, Qu J, et al. The toxicity of metallic nanoparticles on liver: The subcellular damages, mechanisms, and outcomes. International Journal of Nanomedicine. 2019; 14: 8787-8804 doi: 10.2147/IJN.S212907

35. Kohi NH, Rasooli A, Hajihosseini R, et al. Considering the Zataria multiflora essential oil effect on the xenobiotic metabolism in acute toxicity induced by iron nanoparticle. Journal of Animal Research. 2018; 31: 172-182.

36. Shokrzadeh M, Chabra A, Ahmadi A, et al. Hepatoprotective effects of Zataria multiflora ethanolic extract on liver toxicity induced by cyclophosphamide in mice. Drug Res. 2015; 65: 169-175. doi: 10.1055/s0034-1370932

37. Sarwar R, Pierce N, Koppe S. Obesity and nonalcoholic fatty liver disease: current perspectives. Diabetes, Metabolic Syndrome and Obesity: Targets and Therapy. 2018; 11: 533-542. doi: 10.2147/DMSO.S146339

38. Kavoosi G. Zataria multiflora essential oil reduces diabetic damages in streptozotocin-induced diabetic rats. African Journal of Biotechnology 2011; 10: 17632-17639.

39. Mahmoodi M, Koohpeyma F, Saki F, et al. The protective effect of Zataria multiflora Boiss. hydroalcoholic extract on TNF-a production, oxidative stress, and insulin level in streptozotocin-induced diabetic rats. Avicenna Journal of Phytomedicine. 2019; 9: 72-83.

40. Khoshvaghti A, Nazifi S, Derakhshaniyan S, et al. The Effects of Zataria multiflora hydroalcoholic extract on some liver enzymes, cholesterol, triglyceride, HDL-Cholesterol, LDL Cholesterol, Albumin and Total Protein in Rat. J Basic Appl Sci. 2012; 8: 217-222.

41. Mohammadi A, Gholamhoseinian A, Fallah H. Zataria multiflora increases insulin sensitivity and PPAR $\gamma$ gene expression in high fructose fed insulin resistant rats. Iran J Basic Med Sci. 2014; 17: 263-270.

42. Pedrosa I, Saíz A, Arrazola J, et al. Hydatid disease: Radiologic and pathologic features and complications. 2000; 20: 795-817. doi: 10.1148/ radiographics.20.3.g00ma06795

43. Moazeni M, Larki S, Saharkhiz MJ, et al. In vivo study of the efficacy of the aromatic water of Zataria multiflora on hydatid cysts. Antimicrob Agents Chemother. 2014; 58: 6003-6008. doi: 10.1128/aac.02963-14

44. Moazeni M, Larki S, Oryan A, et al. Preventive and therapeutic effects of Zataria multiflora methanolic extract on hydatid cyst: an in vivo study. Vet Parasitol. 2014; 205: 107-112. doi: 10.1016/j.vetpar.2014.07.006 45. Oryan A, Moazeni M, Kordshouli F. Administration of Zataria multiflora as a novel therapeutic strategy in destruction of the germinal layer of hydatid cyst. Research Journal of Parasitology. 2016; 11: 41-47. doi: 10.3923/jp.2016.41.47 
46. Al-abodi HR, Al-Shadeedi SMJ, K.Z.K A-A, et al. Zataria multiflora Bois as an auspicious therapeutic approach against Echinococcus granulosus: Current status and future perspectives. Comparative Immunology, Microbiology and Infectious Diseases. 2019; 66: 101335. doi: https:// doi.org/10.1016/j.cimid.2019.101335

47. Atayi Z, Borji H, Moazeni M, et al. Zataria multiflora would attenuate the hepatotoxicity of long-term albendazole treatment in mice with cystic echinococcosis. Parasitology International. 2018; 67: 184-187. doi: 10.1016/j.parint.2017.11.007

48. Zamani N, Shams M, Nimrouzi M, et al. The effects of Zataria multiflora Boiss. (Shirazi thyme) on nonalcoholic fatty liver disease and insulin resistance: A randomized double-blind placebo-controlled clinical trial. Complement Ther Med. 2018; 41: 118-123. doi: 10.1016/j. ctim.2018.09.010

49. Khazdair MR, Rajabi O, Balali-Mood M, et al. The effect of Zataria multiflora on pulmonary function tests, hematological and oxidant/ antioxidant parameters in sulfur mustard exposed veterans, a randomized doubled-blind clinical trial. Environ Toxicol Pharmacol. 2018; 58: 180-188. doi: 10.1016/j.etap.2018.01.006

50. Nazari A, Mahmazi S, Sahraian Z. Evaluation of Zataria multiflora Boiss. (Shirazi Thyme) hydro alcoholic extract effect on proinflammatory cytokine IL-6 different transcript variants expression level in mesenchymal stem cells (MSCs). Gene, Cell and Tissue. 2018; 5: e82463. doi: 10.5812/gct.82463

51. Aristatile B, Al-Numair KS, Veeramani C, et al. Effect of carvacrol on hepatic marker enzymes and antioxidant status in D-galactosamineinduced hepatotoxicity in rats. Journal Fundamental Clinical Pharmacology. 2009; 23: 757-765.

52. Nafees S, Ahmad ST, Arjumand W, et al. Carvacrol ameliorates thioacetamide-induced hepatotoxicity by abrogation of oxidative stress, inflammation, and apoptosis in liver of Wistar rats. Hum Exp Toxicol. 2013; 32: 1292-1304. doi: 10.1177/0960327113499047

53. Aristatile B, Al-Numair KS, Veeramani C, et al. Effect of carvacrol on hepatic marker enzymes and antioxidant status in D-galactosamineinduced hepatotoxicity in rats. Fundamental \& Clinical Pharmacology. 2009; 23: 757-765. doi: 10.1111/j.1472-8206.2009.00721.x

54. Palabiyik S, Karakus E, Halici Z, et al. The protective effects of carvacrol and thymol against paracetamol-induced toxicity on human hepatocellular carcinoma cell lines (HepG2). Human \& Experimental Toxicology. 2016; 35. doi: 10.1177/0960327115627688

55. Bakır M, Geyikoglu F, Colak S, et al. The carvacrol ameliorates acute pancreatitis-induced liver injury via antioxidant response. Cytotechnology. 2016; 68: 1131-1146. doi: 10.1007/s10616-015-9871-z

56. Abd El Aal HA, Ahmed LA, Hassan WA, et al. Combination of carvacrol with simvastatin improves the lipid-lowering efficacy and alleviates simvastatin side effects. Journal of Biochemical and Molecular Toxicology. 2017; 31: e21981. doi: 10.1002/jbt.21981

57. Jayakumar S, Madankumar A, Asokkumar S, et al. Potential preventive effect of carvacrol against diethylnitrosamine-induced hepatocellular carcinoma in rats. Mol Cell Biochem. 2012; 360: 51-60. doi: 10.1007/ s11010-011-1043-7

58. Rajan B, Ravikumar R, Premkumar T, et al. Carvacrol attenuates $\mathrm{N}$-nitrosodiethylamine induced liver injury in experimental Wistar rats. Food Science and Human Wellness. 2015; 4: 66-74. doi: https:// doi.org/10.1016/j.fshw.2015.04.002

59. Khazdair MR, Alavinezhad A, Boskabady MH. Carvacrol ameliorates haematological parameters, oxidant/antioxidant biomarkers and pulmonary function tests in patients with sulphur mustard-induced lung disorders: A randomized double-blind clinical trial. J Clin Pharm Ther. 2018; 43: 664-674. doi: 10.1111/jcpt.12684

60. Khazdair MR, Boskabady MH. A double-blind, randomized, placebocontrolled clinical trial on the effect of carvacrol on serum cytokine levels and pulmonary function tests in sulfur mustard induced lung injury. Cytokine. 2019; 113: 311-318. doi: 10.1016/j.cyto.2018.07.031

61. Alam K, Nagi MN, Badary OA, et al. The protective action of thymol against carbon tetrachloride hepatotoxicity in mice. Pharmacological Research. 1999; 40: 159-163. doi: https://doi.org/10.1006/phrs.1999.0472

62. Özkan A, Erdogan A. A comparative evaluation of antioxidant and anticancer activity of essential oil from Origanum onites (Lamiaceae) and its two major phenolic components. Turkish Journal of Biology. 2011; 35: 735-742. doi: 10.3906/biy-1011-170

63. Al-Awaida W, Akash M. Protective role of aqueous medicinal herbal extracts against oxidative stress on Glucose-6-phosphate dehydrogenase activity and RBC fragility. Life Science Journal. 2014; 11: 385-391.

64. Rašković A, Pavlović N, Kvrgić M, et al. Effects of pharmaceutical formulations containing thyme on carbon tetrachloride-induced liver injury in rats. BMC Complement Altern Med. 2015; 15: 442 . doi: 10.1186/ s12906-015-0966-Z

65. Placha I, Takacova J, Ryzner M, et al. Effect of thyme essential oil and selenium on intestine integrity and antioxidant status of broilers. J British Poultry Science. 2014; 55: 105-114.

66. Nobakht M, Darmanikuhi H, Mohiti-Asli M. Effects of Zataria multiflora boiss (thyme) extract and dietary fat on performance and carcass antioxidant properties in broiler chicks. Animal Science Journal. 2017; 117: 117-128.

67. Rubió L, Serra A, Chen CY, et al. Effect of the co-occurring components from olive oil and thyme extracts on the antioxidant status and its bioavailability in an acute ingestion in rats. Food Funct. 2014; 5: 740-747. doi: $10.1039 / \mathrm{c} 3$ fo6 $0446 \mathrm{~b}$ 